\title{
Ionic conduction mechanisms of apatite-type lanthanum silicate and germanate from first principles
}

\author{
Katsuyuki MATSUNAGA ${ }^{* * *, \dagger}$ \\ *Department of Materials Physics, Nagoya University, Furo, Chikusa, Nagoya 464-8603, Japan \\ **Nanostructure Research Laboratory, Japan Fine Ceramies Center, 2-4-1 Mutsuno, Astuta, Nagoya 456-8587, Japan
}

\begin{abstract}
Ionic conduction mechanisms in apatite-type lanthanum silicate and germanate studied by first-principles calculations were reviewed, along with the ones previously proposed by experiments and atomistic simulations. It was found that the most stable interstitial oxygen sites in $\mathrm{La}_{10}\left(\mathrm{SiO}_{4}\right)_{6} \mathrm{O}_{3}$ are located at the vicinity of the $\mathrm{O} 4$ column and the metastable sites are present between $\mathrm{SiO}_{4}$ tetrahedra. In contrast, $\mathrm{La}_{10}\left(\mathrm{GeO}_{4}\right)_{6} \mathrm{O}_{3}$ showed the most stable sites between $\mathrm{GeO}_{4}$ tetrahedra, forming $\mathrm{Ge}_{2} \mathrm{O}_{9}$ units. These can reasonably explain interstitial sites reported experimentally. The fundamental mechanism for ionic conduction in both systems is the interstitialcy mechanism, where interstitial oxygen ions and oxygen ions at regular lattice sites undergo cooperative motion through the lattices. In particular, the interstitialcy mechanism via $\mathrm{Si} / \mathrm{GeO}_{4}$ tetrahedra takes place by sequential bondforming and bond-breaking events between $\mathrm{Si} / \mathrm{Ge}$ and oxygen ions, and play an important role to realize rapid ionic conduction. (C2017 The Ceramic Society of Japan. All rights reserved.
\end{abstract}

Key-words : First-principles calculation, Apatite-type ionic conductor, Potential barrier, lonic conduction pathway

[Received April 28, 2017; Accepted June 29, 2017]

\section{Introduction}

Oxygen ion conductors are important for solid oxide fuel cells (SOFCs) and oxygen sensors. A conventional electrolyte for SOFC is yttria stabilized zirconia, and its excellent oxygen ion conductivity sufficient for SOFC operation can be achieved at relatively high temperatures around $1,000^{\circ} \mathrm{C}$. Alternative electrolytes are expected to be used at the lower temperatures, and a variety of oxides are being investigated. In this class of materials, apatite-type rare-earth silicate and germanate are promising candidates, ${ }^{1-8)}$ and detailed knowledge on their oxygen ion conduction mechanism at the atomic scale is required to further improve their oxygen ion conductivities for practical application to SOFC.

A number of experimental and theoretical researches for rareearth (Ln) silicate and germanate were performed to reveal the oxygen ion conduction mechanism. Since the highest ionic conductivity was found for $\mathrm{Ln}^{3+}=\mathrm{La}^{3+},{ }^{1)}$ many of the previous studies focused on lanthanum silicate $\left[\mathrm{La}_{9.33+x}\left(\mathrm{SiO}_{4}\right)_{6} \mathrm{O}_{2+1.5 x}\right]$ and germanate $\left[\mathrm{La}_{9.33+x}\left(\mathrm{GeO}_{4}\right)_{6} \mathrm{O}_{2+1.5 x}\right.$ ]. Figure 1 displays the crystal structure of $\mathrm{La}_{10}\left(\mathrm{SiO}_{4}\right)_{6} \mathrm{O}_{3}$ that is composed of two different $\mathrm{La}$ sites ( $\mathrm{La} 1$ and $\mathrm{La} 2$ ), one kind of $\mathrm{Si}$ site forming $\mathrm{SiO}_{4}$ tetrahedra with three different oxygen atoms (O1-O3), and one more oxygen site (O4) arranging along the $c$ axis (called as "O4 column"). ${ }^{9}$ The La2 sites forming triangles around the O4 columns are considered to be fully occupied, while the Lal sites forming atomic columns along the $c$ axis involves at most $17 \%$ of vacancies when $x=0.0$. At the La composition of more than $x=0.0$, excess oxygen ions should be introduced into the crystal due to charge neutrality requirement. From this characteristic crystal structure, it can be speculated that the chemical composition of $x$ and excess oxygen atoms as well as $\mathrm{O} 4$ ions forming the columnar structure might play an important role for the rapid oxygen ion conduction observed experimentally.

Corresponding author: K. Matsunaga; E-mail: kmatsunaga@ nagoya-u.jp
In the early days, an ionic conduction mechanism of stoichiometric $\mathrm{La}_{9.33}\left(\mathrm{SiO}_{4}\right)_{6} \mathrm{O}_{2}$ was investigated by atomistic simulations with empirical interatomic potentials. Tolchard et al. performed static lattice simulations of $\mathrm{La}_{9.33}\left(\mathrm{SiO}_{4}\right)_{6} \mathrm{O}_{2}$ and proposed that interstitial oxygen ions are present and exhibit the non-linear "sinusoidal-like" pathway along the $c$ axis. ${ }^{10), 11)}$ Although the stoichiometric phase does not involve excess oxygen ions explicitly, the authors suggested the presence of interstitial oxygen ions coming from the $\mathrm{O} 4$ column. Based on the experimental neutron diffraction study, ${ }^{12}$ it is thought that the La vacancies induce the disorder in the $\mathrm{O} 4$ column and promote interstitial oxygen ions to go out of the $\mathrm{O} 4$ columns, which corresponds to formation of oxygen Frenkel defects. In this case, $\mathrm{O} 4$ vacancies formed by the Frenkel reaction can also promote ionic conduction along the O4 column via a vacancy mechanism, so that the area surrounded by $\mathrm{La} 2$ ions and centered at the $\mathrm{O} 4$ column serve as rapid ionic conduction channels ("O4 channel"). However, X-ray diffraction analyses for the stoichiometric phase by Okudera et al. did not detect the presence of interstitial oxygen ions and showed large anisotropy in O4-ion motion, which suggests the linear conduction pathway running through the $\mathrm{O} 4$ column. ${ }^{13)}$ Kendrick et al. performed molecular dynamics simulation of $\mathrm{La}_{9.33}\left(\mathrm{SiO}_{4}\right)_{6} \mathrm{O}_{2}{ }^{14}{ }^{14}$ They also supported the sinusoidal-like interstitial mechanism in the $\mathrm{O} 4$ channels, and also found the slightly different behavior of the moving interstitial oxygen ions (the " $\mathrm{S}_{\mathrm{N}} 2$-type" process) between $\mathrm{O} 4$ channels, where the interstitial oxygen ions diffuse even normal to the $c$ axis interacting with $\mathrm{SiO}_{4}$ units. In contrast, Béchade et al. applied static lattice simulations and the bond valence method for stoichiometric $\mathrm{La}_{9.33}\left(\mathrm{SiO}_{4}\right)_{6} \mathrm{O}_{2}$, and proposed the push-pull mechanism, where interstitial oxygen ions do not diffuse through the $\mathrm{O} 4$ channel independently but undergo cooperative movement with $\mathrm{O} 4$ ions. ${ }^{15)}$

Regarding the oxygen-excess phase of $\mathrm{La}_{9.33+x}\left(\mathrm{SiO}_{4}\right)_{6} \mathrm{O}_{2+1.5 x}$ $(x>0.0)$, static lattice simulations by Jones et al. indicated that the interstitial oxygen ions are located at the periphery of the $\mathrm{O} 4$ channel to form " $\mathrm{SiO}_{5}$ " units with the adjacent $\mathrm{SiO}_{4}$ tetrahedra 
(a)

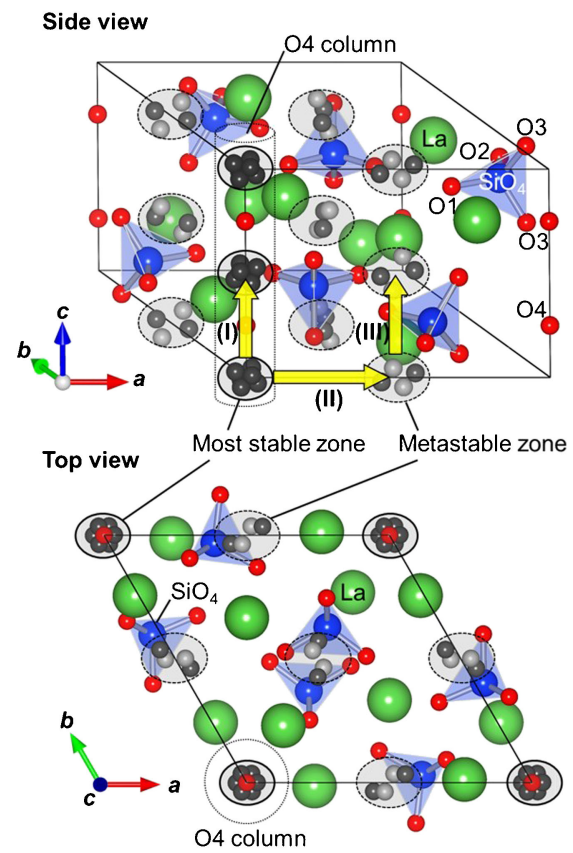

(b)

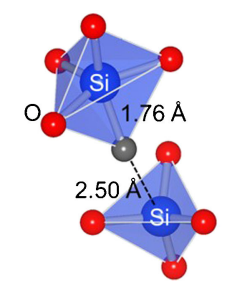

Fig. 1. (a) Crystal structure of $\mathrm{La}_{10}\left(\mathrm{SiO}_{4}\right)_{6} \mathrm{O}_{3}$ along with the most stable (black balls) and metastable (gray and white balls) interstitial oxygen sites. (b) The local atomic structure around the interstitial oxygen ion at the second most stable position. ${ }^{9)}$ (CIOP Publishing. Reproduced with permission. All rights reserved.

and diffuse from one $\mathrm{SiO}_{4}$ tetrahedron to another (the "handover" mechanism). ${ }^{16)}$ Neutron diffraction analyses of $\mathrm{La}_{9.69^{-}}$ $\left(\mathrm{Si}_{5.70} \mathrm{Mg}_{0.30}\right) \mathrm{O}_{26.24}$ at high temperatures by Ali et al. showed that the interstitial oxygen ions (O5) are present at the periphery of the $\mathrm{O} 4$ channel. ${ }^{17)}$ However, the authors observed the unusual anisotropic atomic distribution of $\mathrm{O} 4$ along the $\mathrm{O} 4$ column as well as the "U-shaped" oxygen densities of O3-O5-O3 perpendicular to the $c$ axis. Based on these results, they proposed the dual oxygen ion conduction mechanism; the $\mathrm{O} 4$ ions along the $\mathrm{O} 4$ column diffuse via a vacancy mechanism and the interstitial oxygen ions move normal to the $c$ axis via an interstitial mechanism.

There are a smaller number of researches on ionic conduction mechanism in lanthanum germanate, as compared to those in lanthanum silicate. Kendrick et al. performed static lattice and molecular dynamics simulations of stoichiometric $\mathrm{La}_{9.33^{-}}$ $\left(\mathrm{GeO}_{4}\right)_{6} \mathrm{O}_{2}{ }^{18)}$ These authors showed that the oxygen Frenkel defects are formed in the $\mathrm{O} 4$ channel and the interstitial oxygen ions are located close to $\mathrm{GeO}_{4}$ tetrahedra adjacent to the $\mathrm{O} 4$ channels. The location of the interstitial oxygen ions is in reasonable agreement with the one from experimental neutron diffraction analyses for oxygen excess $\mathrm{La}_{10}\left(\mathrm{GeO}_{4}\right)_{6} \mathrm{O}_{3}$ by Pramana et al. ${ }^{19)}$ In their conduction mechanism, $\mathrm{O} 4$ ions move in the column via O4 vacancies, and the interstitial oxygen ions move along the $c$ axis by the "fan-like" mechanism, where the interstitials diffuse between $\mathrm{GeO}_{4}$ tetrahedra. León-Reina et al. suggested from neutron diffraction analyses and electrical conductivity measurements that the electrical conduction of oxygen excess $\mathrm{La}_{9.60^{-}}$ $\left(\mathrm{GeO}_{4}\right)_{6} \mathrm{O}_{2.40}$ takes place by both oxygen vacancies and interstitials at low temperatures while by only interstitials at high temperatures. ${ }^{20)}$ Molecular dynamics simulations using empirical interatomic potentials for $\mathrm{La}_{8} \mathrm{Y}_{2}\left(\mathrm{GeO}_{4}\right)_{6} \mathrm{O}_{3}$ by Panchmatia et al. proposed a $\mathrm{S}_{\mathrm{N}}$ 2-type mechanism for interstitial oxygen conduction occurring between $\mathrm{GeO}_{4}$ tetrahedra, which is the major pathway giving rise to the anisotropic ionic conduction perpendicular to the $c$ axis. ${ }^{21)}$

As stated above, a variety of atomic-level mechanisms for ionic conduction in lanthanum silicate and germanate were proposed, and yet there is no consensus on the ionic conduction mechanism for the two systems. From a theoretical viewpoint, however, it is worth mentioning that most of previous studies used atomistic simulations with empirical or semiempirical interatomic potentials. Since their potential parameters are generally determined based on physical properties of reference perfect crystals, there is still ambiguity with respect to treatment of defects and their related diffusing ions. In this regard, first-principles calculations based on the density functional theory proved to be more accurate and reliable for dealing with atomic structures and energetics of lattice defects, even without any reference experimental data. For example, this can also be confirmed from the fact that our previous first-principles calculations on proton conductors provide their activation energies for ionic conduction that reasonably agree with available experimental data. ${ }^{22), 23)}$ In this paper, I would like to review the ionic conduction mechanisms in lanthanum silicate and germanate revealed in a first-principles manner, and to discuss them along with the mechanisms previously proposed.

\section{Computational method}

In our study, potential barriers and pathways for ionic conduction in lanthanum silicate and germanate were investigated in a first-principles manner. Details of the computational conditions can be found elsewhere, ${ }^{9)}$ and some of important items are briefly described here.

First-principles calculations were performed with the projector augmented wave method implemented in the VASP code. ${ }^{24), 25)}$ The generalized gradient approximation (GGA) parameterized by Perdew, Burke, and Ernzerhof (GGA-PBE) was employed for exchange-correlation interactions between electrons. ${ }^{26)}$ Electronic wavefunctions were expanded by plane waves with a cutoff energy up to $400 \mathrm{eV}$.

As stated in the introduction, ionic conductivities and their mechanisms of lanthanum silicate and germanate [ $\mathrm{La}_{9.33+x}(\mathrm{Si} /$ $\left.\mathrm{GeO}_{4}\right)_{6} \mathrm{O}_{2+1.5 x}$ ] may depend on the composition $x$. Lal sites involve more La vacancies for smaller $x$, which lowers the crystal symmetry and thus makes first-principles calculations on ionic conduction pathways more demanding. In order to avoid such a difficulty, the composition $x=0.67$ was mainly focused, namely $\mathrm{La}_{10}\left(\mathrm{Si} / \mathrm{GeO}_{4}\right)_{6} \mathrm{O}_{3}$. Supercells were generated by extending the hexagonal unit cell of $\left[\mathrm{La}_{10}\left(\mathrm{Si} / \mathrm{GeO}_{4}\right)_{6} \mathrm{O}_{2}\right]^{2+}$ by $1 \times 1 \times 3$ (triply repeated toward the $c$ axis), which were used as the host lattice. One interstitial oxygen ion was introduced in the supercell, and its low-energy sites and conduction pathways were calculated. It is noted here that one interstitial oxygen ion is involved in every unit cell at the chemical composition of $x=0.67$. However, only one interstitial oxygen ion was considered in the supercells, in order to minimize interactions between the interstitials and extract the intrinsic potential energy surface of every single 
interstitial oxygen ion. Brillouin zone integration for the supercells was performed with a k-point mesh of $2 \times 2 \times 1$. Energy profiles of all possible conduction pathways between low-energy interstitial sites were evaluated with the nudged elastic band (NEB) method. ${ }^{27)}$

\section{Low-energy interstitial sites}

Determination of low-energy interstitial oxygen sites is an important step to reveal potential barriers and pathways for ionic conduction. In this study, low-energy interstitial oxygen sites were searched initially, and the ones having potential energies of less than $1.0 \mathrm{eV}$ with respect to that of the most stable site were determined. This is because the activation energies for ionic conduction in lanthanum silicate and germanate were experimentally reported to be around $0.5-0.8 \mathrm{eV}^{7)}$ and thus a potential energy difference between the most stable and the other low-energy sites should be less than the range of the values.

Figure 1 displays locations of the most stable and metastable interstitial oxygen sites in $\mathrm{La}_{10}\left(\mathrm{SiO}_{4}\right)_{6} \mathrm{O}_{3}$, determined from our first-principles calculations. ${ }^{9)}$ In this figure, crystallographically equivalent interstitial sites are drawn according to the original $\mathrm{P}_{3} / \mathrm{m}$ symmetry. The most stable sites are located at the vicinity of the $\mathrm{O} 4$ columns. The second and third most stable interstitial sites are present between $\mathrm{SiO}_{4}$ tetrahedra, and have larger potential energies by 0.29 and $0.49 \mathrm{eV}$, respectively, than the most stable site. This most stable site is very close to the interstitial site determined experimentally for $\mathrm{La}_{8.65} \mathrm{Sr}_{1.35}\left(\mathrm{SiO}_{4}\right)_{6} \mathrm{O}_{2.32}$ by LeónReina et al. ${ }^{28)}$ It should be noted, however, that the interstitial sites reported previously vary depending on experiments: neutron diffraction studies demonstrated the site in the periphery of the $\mathrm{O} 4$ channel (close to $\mathrm{La}_{2}$ and a $\mathrm{SiO}_{4}$ tetrahedron) for stoichiometric $\mathrm{La}_{9.33}\left(\mathrm{SiO}_{4}\right)_{6} \mathrm{O}_{2}{ }^{29)}$ and oxygen-excess $\mathrm{La}_{9.55}\left(\mathrm{SiO}_{4}\right)_{6} \mathrm{O}_{2.32},{ }^{20)}$ and the one lying halfway between $\mathrm{O} 4$ and a $\mathrm{SiO}_{4}$ unit for $\mathrm{La}_{9.69-}$ $\left(\mathrm{Si}_{5.70} \mathrm{Mg}_{0.30} \mathrm{O}_{4}\right)_{6} \mathrm{O}_{2.24}{ }^{17)}$ and $\left.\mathrm{La}_{9.71}\left(\mathrm{Si}_{5.81} \mathrm{Mg}_{0.18} \mathrm{O}_{4}\right)_{6} \mathrm{O}_{2.37 .}{ }^{30}\right)$

At the second and third most stable sites, the interstitial oxygen ions interact with the surrounding $\mathrm{SiO}_{4}$ tetrahedra. In fact, the interstitial forms the $\mathrm{SiO}_{5}$ unit, as shown in Fig. 1(b). Such an interaction between $\mathrm{SiO}_{4}$ and interstitial oxygen ion was also pointed out experimentally by ${ }^{29} \mathrm{Si} \mathrm{NMR}$ measurements for stoichiometric $\mathrm{La}_{9.33}\left(\mathrm{SiO}_{4}\right)_{6} \mathrm{O}_{2}$ and oxygen-excess $\mathrm{La}_{9.67}\left(\mathrm{SiO}_{4}\right)_{6}$ $\mathrm{O}_{2.5} \cdot{ }^{31)}$ Moreover, it is worth mentioning here that, although the second most stable interstitial site appears to be quite different from the interstitial sites previously reported (at the periphery of the $\mathrm{O} 4$ channel), formation of the $\mathrm{SiO}_{5}$ unit results in protrusion of an oxygen ion of $\mathrm{SiO}_{5}$ toward the periphery of the $\mathrm{O} 4$ channel, as shown in Fig. 2. This protruded oxygen site is actually in good agreement with the interstitial sites reported for stoichiometric $\mathrm{La}_{9.33}\left(\mathrm{SiO}_{4}\right)_{6} \mathrm{O}_{2}{ }^{29)}$ and oxygen-excess $\mathrm{La}_{9.55}\left(\mathrm{SiO}_{4}\right)_{6} \mathrm{O}_{2.32 .}{ }^{20)} \mathrm{Nev}-$ ertheless, this interstitial site at the periphery of the $\mathrm{O} 4$ channel has a larger potential energy by $0.29 \mathrm{eV}$, as compared to the most stable site, but the relative stability of the interstitial sites might be affected by dopants and/or La vacancies involved in real materials. In fact, our previous calculations of stoichiometric $\mathrm{La}_{9.33}\left(\mathrm{SiO}_{4}\right)_{6} \mathrm{O}_{2}$ showed that the second or third most stable interstitial sites (close to $\mathrm{SiO}_{4}$ tetrahedra) are by only $0.04-0.06$ $\mathrm{eV}$ higher in energy than the most stable one (close to the $\mathrm{O} 4$ column). ${ }^{32)}$ La vacancies or dopants might lower the crystal symmetry and modulate the potential energy surface of $\mathrm{La}_{10^{-}}$ $\left(\mathrm{SiO}_{4}\right)_{6} \mathrm{O}_{3}$, so that it can be speculated that the second most stable interstitial sites theoretically predicted could have been observed in real materials.

Unlike the silicate case, the most stable interstitial oxygen site in $\mathrm{La}_{10}\left(\mathrm{GeO}_{4}\right)_{6} \mathrm{O}_{3}$ was found at the center between two $\mathrm{GeO}_{4}$

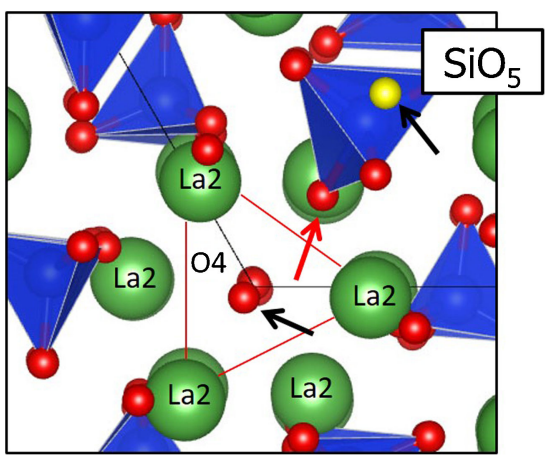

Fig. 2. The most stable (close to the $\mathrm{O} 4$ column denoted by the black arrow) and the second most stable (yellow ball) interstitial oxygen site in $\mathrm{La}_{10}\left(\mathrm{SiO}_{4}\right)_{6} \mathrm{O}_{3}$, viewed along the $c$ axis. The protruded oxygen ion of the $\mathrm{SiO}_{5}$ unit is highlighted by the red arrow, which is close to the interstitial sites reported in some of previous experiments. (a)

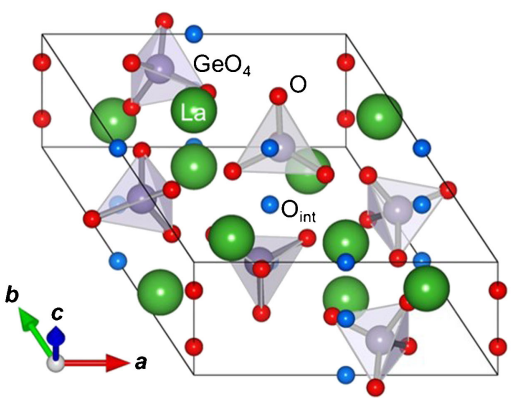

(b)

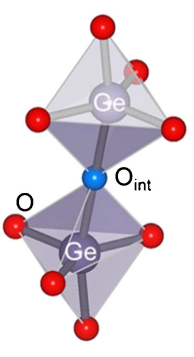

Fig. 3. (a) The most stable interstitial oxygen sites in $\mathrm{La}_{10}\left(\mathrm{GeO}_{4}\right)_{6} \mathrm{O}_{3}$ displayed by blue balls. (b) The local atomic structure around the interstitial oxygen ion at the most stable position. ${ }^{33)}$

tetrahedra, forming the $\mathrm{Ge}_{2} \mathrm{O}_{9}$ unit (see Fig. 3). ${ }^{33)}$ Other lowenergy sites have potential energies of more than $1.0 \mathrm{eV}$ with reference to the most stable site, and it is thus interesting that $\mathrm{La}_{10}\left(\mathrm{GeO}_{4}\right)_{6} \mathrm{O}_{3}$ does not have any low-energy sites inside the O4 channel. Although less experimental data on the interstitial oxygen site in lanthanum germanate were reported, as compared with lanthanum silicate, neutron diffraction analyses for $\mathrm{La}_{10^{-}}$ $\left(\mathrm{GeO}_{4}\right)_{6} \mathrm{O}_{3}$ by Pramana et al. $\left.{ }^{19}\right)$ demonstrated the interstitial oxygen site close to $\mathrm{GeO}_{4}$ tetrahedra. These authors mentioned formation of $\mathrm{GeO}_{5}$ units by an interstitial oxygen ion, which strongly supports the interstitial sites between $\mathrm{GeO}_{4}$ tetrahedra obtained in our study. It is noted, however, that the similar analyses for $\mathrm{La}_{9.60}\left(\mathrm{GeO}_{4}\right)_{6} \mathrm{O}_{2.4}$ by León-Reina et al. ${ }^{20)}$ showed a different interstitial site at the periphery of the $\mathrm{O} 4$ channel.

As shown above, the most stable interstitial sites for the two systems of silicate and germanate are different. The most stable interstitial position was located close to the $\mathrm{O} 4$ column in lanthanum silicate, whereas that was present between $\mathrm{GeO}_{4}$ tetrahedra in lanthanum germanate. Such a difference may be closely related to a difference in interaction between $\mathrm{Si}-\mathrm{O}$ and $\mathrm{Ge}-\mathrm{O}$. It is well known that $\mathrm{SiO}_{2}$ has a number of polymorphs at ambient pressure but their fundamental structural unit around $\mathrm{Si}$ can be described by $\mathrm{SiO}_{4}$ tetrahedra, expect for that in the stishovite phase under higher pressures. In contrast, $\mathrm{GeO}_{2}$ has four-fold and six-fold coordinated $\mathrm{Ge}$ ions with oxygen ions in the hexagonal and tetragonal phase $^{34)}$ produced at ambient pressure, respectively. Such versatile coordination numbers of Ge ions might have a close relationship with the fact that the interstitial oxygen ions tend to favorably attach $\mathrm{GeO}_{4}$ tetrahedra in lanthanum germanate. 


\section{Ionic conduction mechanism of lanthanum silicate}

Three kinds of conduction pathways connecting two adjacent interstitial oxygen sites [(I), (II), and (III)] can be considered in $\mathrm{La}_{10}\left(\mathrm{SiO}_{4}\right)_{6} \mathrm{O}_{3}$ [see Fig. 1(a)]. In the case of the pathway (I), the interstitial oxygen ion moves between the most stable interstitial sites along the $\mathrm{O} 4$ cloumn. However, it is then necessary to consider which type of conduction mechanism works for the pathway. One possible mechanism is a simple interstitial mechanism, where the interstitial oxygen ion directly jumps into an adjacent unoccupied interstitial site. Another mechanism is an interstitialcy mechanism that accompanies cooperative motion of interstitial oxygen and $\mathrm{O} 4$ like the push-pull mechanism. ${ }^{15)}$ In addition, some of the previous studies proposed a vacancy mechanism in the $\mathrm{O} 4$ channel, where an oxygen vacancy of the $\mathrm{O} 4$ column induces rapid ionic conduction along the $\mathrm{O} 4$ column.

Figure 4 shows trajectories of the interstitial oxygen and the cooperating oxygen ions in $\mathrm{La}_{10}\left(\mathrm{SiO}_{4}\right)_{6} \mathrm{O}_{3}$. In the interstitial mechanism [see Fig. 4(a)], the interstitial oxygen ion at the most stable site moves toward the $c$ axis and yet significantly swerves from the $\mathrm{O} 4$ column. This is mainly because of presence of the adjacent $\mathrm{O} 4$ ion. The moving interstitial oxygen ion suffers electrostatic repulsion with an $\mathrm{O} 4$ ion located ahead, and thus has to overtake the $\mathrm{O} 4$ ion. Moreover, the interstitial oxygen ion has attractive interactions with $\mathrm{Si}^{4+}$ of the adjacent $\mathrm{SiO}_{4}$ unit in an intermediate state of the diffusion, which also contributes to the shape of the trajectory. The trajectory resembles the one for the non-linear sinusoidal pathway. ${ }^{10), 11)}$ It was found that the calculated potential barrier for this trajectory is $0.88 \mathrm{eV}$.
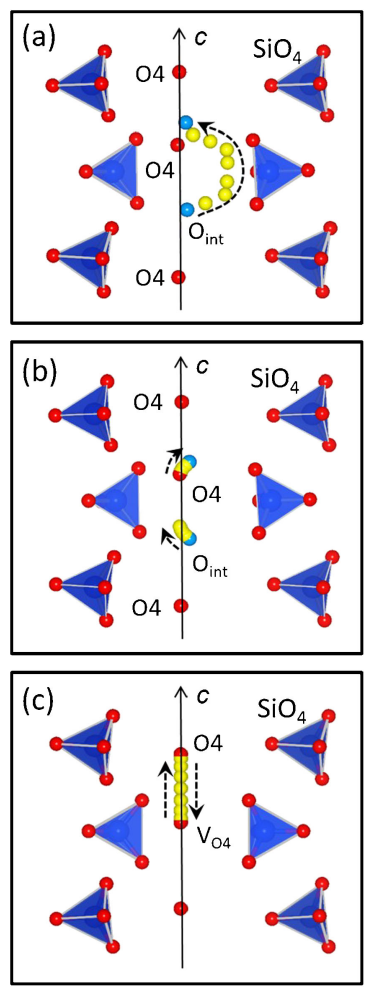

Fig. 4. Trajectories of interstitial oxygen ions (yellow balls) along the $c$ axis in $\mathrm{La}_{10}\left(\mathrm{SiO}_{4}\right)_{6} \mathrm{O}_{3}$ by different mechanisms: (a) the interstitial mechanism, (b) the interstitialcy mechanism, and (c) the vacancy mechanism. Blue and red balls indicate oxygen ions at the interstitial sites and regular lattice sites, respectively.
In contrast, when it is assumed that the interstitial oxygen ion diffuses via the interstitialcy mechanism [see Fig. 4(b)], the interstitial oxygen ion goes into the adjacent $\mathrm{O} 4$ site at a very short distance of $0.07 \mathrm{~nm}$ and subsequently the adjacent $\mathrm{O} 4$ ion is pushed into the adjacent interstitial site. This corresponds to the push-pull mechanism proposed by Béchade et al. ${ }^{15)}$ It is interesting to see that the calculated potential barrier is less than 0.01 $\mathrm{eV}$, which is significantly low compared with potential barriers expected for conventional ionic conductors.

It was also found that ionic conduction of $\mathrm{O} 4$ ions in the presence of the $\mathrm{O} 4$ vacancy results in the straight trajectory with a potential barrier of $0.67 \mathrm{eV}$ [see Fig. 4(c)]. It should be noted here that the vacancy mechanism requires formation of the $\mathrm{O} 4$ vacancy. The $\mathrm{O} 4$ Frenkel reaction energy was found to be $3.8 \mathrm{eV}$ [e.g., $3.2 \mathrm{eV}$ for stoichiometric $\mathrm{La}_{9.33}\left(\mathrm{SiO}_{4}\right)_{6} \mathrm{O}_{2}$ ] in our calculations, and thus the potential barrier height for the vacancy mechanism should become larger by this amount of energy. Although the rather straight trajectory is similar to the one calculated theoretically ${ }^{10)}$ and also seems to be closely related to the experimental linear nuclear density distribution in the $\mathrm{O} 4$ column of $\mathrm{La}_{9.69}\left(\mathrm{Si}_{5.70} \mathrm{Mg}_{0.30}\right) \mathrm{O}_{26.24}$ by Ali et al., $\left.{ }^{17}\right)$ the vacancy mechanism is energetically unfavorable. From the results mentioned above, it can be concluded from our first-principles calculations that the interstitialcy mechanism showing the lowest potential barrier height is responsible for ionic conduction inside the $\mathrm{O} 4$ channel.

The similar analyses for the pathways (II) and (III) were made. It was found that the interstitial mechanism is not a favorable mechanism but the interstitialcy mechanism via $\mathrm{SiO}_{4}$ tetrahedra provides lower potential barriers for the two pathways $[0.58 \mathrm{eV}$ for (II) and $0.82 \mathrm{eV}$ for (III)]. In the case of the pathway (II) (see Fig. 5), for example, the interstitial oxygen ion at the most stable site moves toward an oxygen ion of the neighboring $\mathrm{SiO}_{4}$ tetrahedron and the tetrahedral oxygen ion simultaneously approaches the second most stable interstitial site. It is worth mentioning here that this conduction process does not accompany rotation of the $\mathrm{SiO}_{4}$ tetrahedron but involves sequential bond-forming and bondbreaking events of Si-O during the conduction. Repetition of this interstitialcy mechanism gives rise to long-range conduction perpendicular to the $c$ axis (see Fig. 6). ${ }^{9)}$
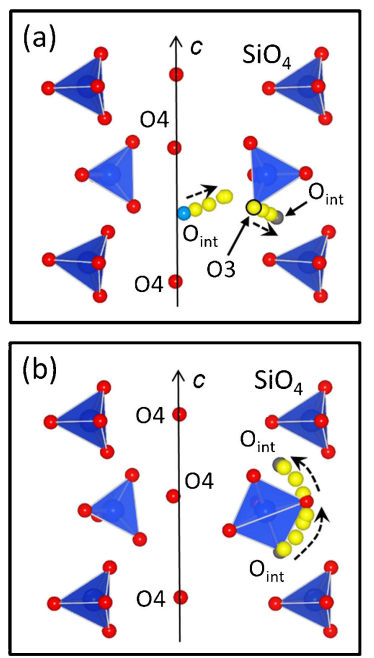

Fig. 5. Trajectories of interstitial oxygen ions (yellow balls) in $\mathrm{La}_{10}\left(\mathrm{SiO}_{4}\right)_{6} \mathrm{O}_{3}$ : (a) the interstitial mechanism normal to the $c$ axis, and (b) the interstitialcy mechanism along the $c$ axis between the metastable interstitial sites. 
The interstitialcy mechanism for the pathway (II) should also have a close relationship with the nuclear density distribution reported by Ali et al. ${ }^{17)}$ The authors observed the "U-shaped" nuclear density distribution of O4-O5-O3 near the periphery of the $\mathrm{O} 4$ channel and especially the largely elongated density distribution of $\mathrm{O} 3$ ions of $\mathrm{SiO}_{4}$ toward perpendicular to the $c$ axis. This can be understood from the trajectory of Fig. 5(a). The interstitial oxygen ion moves to the "O5" site (between the $\mathrm{O} 4$ column and the $\mathrm{SiO}_{4}$ unit) and simultaneously the adjacent $\mathrm{O} 3$ ion of $\mathrm{SiO}_{4}$ is shifted away from the $\mathrm{O} 4$ column. The experimental "U-shaped" nuclear density distribution might reflect such cooperative movement of the oxygen ions.

As stated above, rapid ionic conduction of $\mathrm{La}_{10}\left(\mathrm{SiO}_{4}\right)_{6} \mathrm{O}_{3}$ is realized by the interstitialcy mechanism, irrespective of conduction directions. On the other hand, the potential barriers for the two directions are quite different from each other, which might indicate strong anisotropic ionic conduction of this materials. However, our stochastic kinetic Monte Carlo (KMC) simulations based on the conduction pathways and their potential barriers obtained by first-principles calculations showed that the ionic conduction inside the $\mathrm{O} 4$ channel is considerably more restricted than expected from the extremely low potential barrier. ${ }^{9)}$ This is because blocking the ionic conduction in the $\mathrm{O} 4$ columns occurs. Since interstitial oxygen ions and O4 ions have the extremely low potential barrier by the interstitialcy mechanism, these ions are rather mobile inside the $\mathrm{O} 4$ channel. However, this does not necessarily guarantee rapid long-range ionic conduction of the oxygen ions, and it was observed that the oxygen ions in the $\mathrm{O} 4$ channel cannot overtake neighboring oxygen ions

(a)

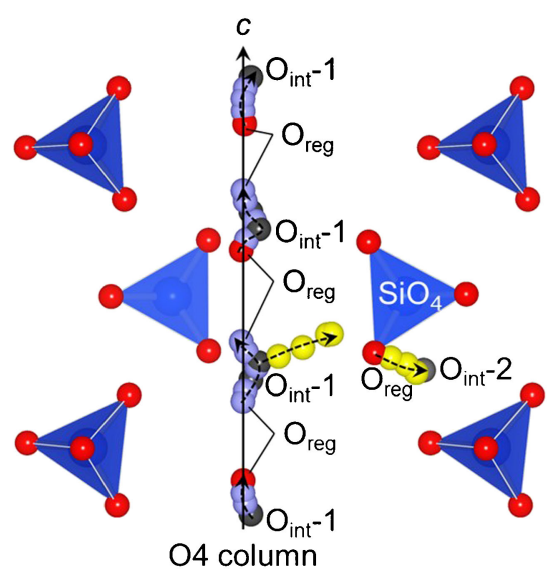

(b)

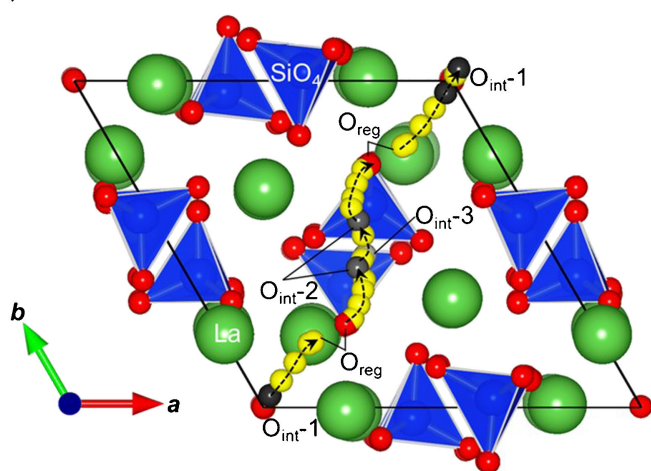

Fig. 6. The long-range oxygen ion conduction pathways (a) along and (b) normal to the $c$ axis in $\left.\mathrm{La}_{10}\left(\mathrm{SiO}_{4}\right)_{6} \mathrm{O}_{3}{ }^{9}{ }^{9}\right) \mathrm{CIOP}$ Publishing. Reproduced with permission. All rights reserved. so that they disturb their long-range diffusion with one another. In other words, the oxygen ions prevent one another from diffusing rapidly along the $c$ axis, and go back and forth repeatedly inside the channel. As a result, the apparent activation energy obtained by KMC simulations is close to the potential barrier for conduction normal to the $c$ axis, suggesting isotropic ionic conduction of $\mathrm{La}_{10}\left(\mathrm{SiO}_{4}\right)_{6} \mathrm{O}_{3}$.

\section{Ionic conduction mechanism of lanthanum germanate}

In the similar way to lanthanum silicate, ionic conduction pathways and their potential barriers in $\mathrm{La}_{10}\left(\mathrm{GeO}_{4}\right)_{6} \mathrm{O}_{3}$ were investigated. It is noted (see Fig. 3) that $\mathrm{La}_{10}\left(\mathrm{GeO}_{4}\right)_{6} \mathrm{O}_{3}$ has six equivalent most stable interstitial sites in the unit cell. Figure 7 shows trajectories of interstitial oxygen ions along the $c$ axis in two different mechanisms. ${ }^{33)}$ In the case of the interstitial mechanism [Fig. 7(a)], the interstitial oxygen ion diffuses around the $\mathrm{GeO}_{4}$ tetrahedron and finally reaches the nearest neighboring interstitial site. While the interstitial oxygen ion pushes the neighboring oxygen ion at the vertex of $\mathrm{GeO}_{4}$ into the adjacent interstitial site by the interstitialcy mechanism [Fig. 7(b)]. As can be seen from the energy profiles for ionic conduction [Fig. 7(c)], the interstitialcy (cooperative) mechanism has a smaller potential barrier $(0.64 \mathrm{eV})$ than the interstitial mechanism $(1.27 \mathrm{eV})$. Therefore, the interstitialcy mechanism via $\mathrm{GeO}_{4}$ tetrahedra is a major mechanism to realize rapid ionic conduction in lanthanum germanate.

Ionic conduction normal to the $c$ axis (along the $a b$ plane) is also expected to be explained by the interstitial or interstitialcy mechanism. It was found that the interstitalcy mechanism gives a smaller potential barrier of $1.17 \mathrm{eV}$ (see Fig. 8) ${ }^{33)}$ It is noted, however, that the interstitialcy mechanism normal to the $c$ axis in this case is a little different from the one found along the $c$ axis (a)

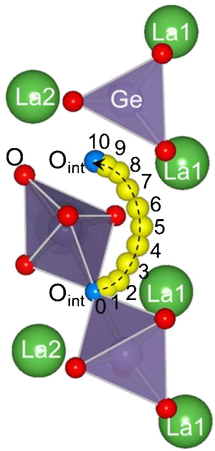

(c)

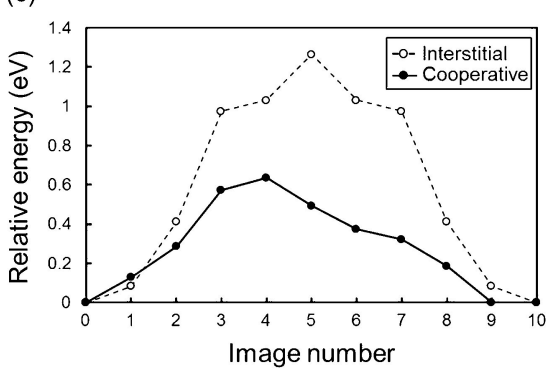

Fig. 7. Trajectories of interstitial oxygen ions (yellow balls) along the $c$ axis in $\mathrm{La}_{10}\left(\mathrm{GeO}_{4}\right)_{6} \mathrm{O}_{3}$ by different mechanisms: (a) the interstitial mechanism, and (b) the interstitialcy mechanism. The potential energy profiles corresponding to the two different mechanisms are plotted in (c). ${ }^{33)}$ 
(a)

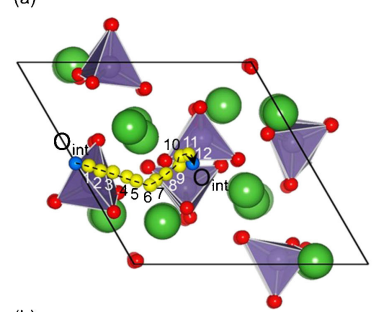

(b)
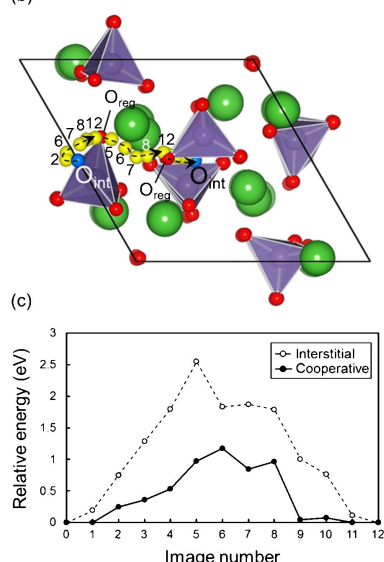

Fig. 8. Trajectories of interstitial oxygen ions (yellow balls) normal to the $c$ axis in $\mathrm{La}_{10}\left(\mathrm{GeO}_{4}\right)_{6} \mathrm{O}_{3}$ by different mechanisms: (a) the interstitial mechanism, and (b) the interstitialcy mechanism. The potential energy profiles corresponding to the two different mechanisms are plotted in (c). ${ }^{33)}$

[Fig. 7(b)], where one interstitial oxygen ion and two oxygen ions of $\mathrm{GeO}_{4}$ tetrahedra are cooperatively involved in the ionic conduction process [see Fig. 8(b)]. This diffusion process looks similar to the one proposed by Panchmatia et al., ${ }^{21)}$ and yet it was found that the calculated potential barrier is about twice higher than that along the $c$ axis $(0.64 \mathrm{eV})$. Therefore, it is not natural to think that such a conduction mechanism normal to the $c$ axis contributes to excellent ionic conductivities of the materials. Otherwise, $\mathrm{La}_{10}\left(\mathrm{GeO}_{4}\right)_{6} \mathrm{O}_{3}$ could have strong anisotropy of the ionic conduction along the $c$ axis.

In order to investigate any other possible conduction mechanism, first-principles molecular dynamics (FPMD) simulations were performed. ${ }^{35)}$ FPMD simulations calculate time-evolution of atomic structures at particular temperature/pressure conditions, so that there is a possibility to find out spontaneous ionic conduction mechanisms. This is quite contrast to the NEB method that assumes particular conduction mechanisms between initial and final states. In fact, the "multi-oxygen ion cooperative mechanism" involving one interstitial oxygen ion, one $\mathrm{O} 4$ ion and two oxygen ions of $\mathrm{GeO}_{4}$ tetrahedron (totally four oxygen ions) was observed from FPMD (Fig. 9). ${ }^{33)}$ This mechanism has a process where an $\mathrm{O} 4$ ion adjacent to the $\mathrm{Ge}_{2} \mathrm{O}_{9}$ unit initially moved out to the nearest interstitial site, forming a $\mathrm{GeO}_{5}$ unit, and simultaneously an oxygen ion of the $\mathrm{Ge}_{2} \mathrm{O}_{9}$ unit moved into the vacant $\mathrm{O} 4$ site. It can be said that the $\mathrm{O} 4$ Frenkel defect formation coincides with its defect annihilation during the mechanism. It was found from the NEB analysis that this cooperative mechanism gives a potential barrier of $0.76 \mathrm{eV}$ [Fig. 9(c)]. This value is much smaller than those predicted by the simple interstitial and interstitialcy mechanisms (Fig. 8), while comparable with the one along the $c$ axis $(0.64 \mathrm{eV})$, shown in Fig. 7. Such a complicated conduction mechanism makes it possible to realize rapid ionic conduction normal to the $c$ axis in $\mathrm{La}_{10}\left(\mathrm{GeO}_{4}\right)_{6} \mathrm{O}_{3}$. (a) Top view

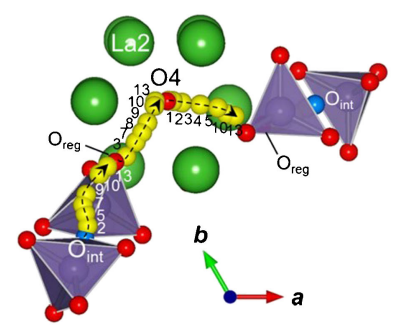

(b) Side view

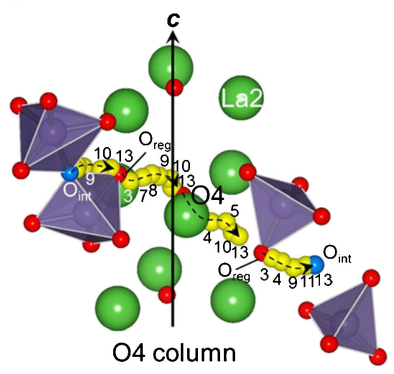

(c)

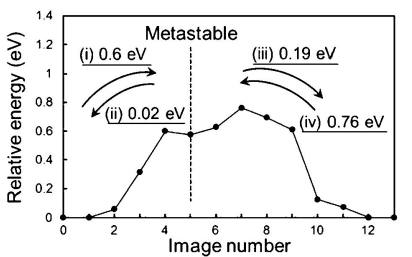

Fig. 9. Trajectories of interstitial oxygen ions (yellow balls) normal to the $c$ axis by the "multi-oxygen ion cooperative mechanism". The corresponding potential energy profile is plotted in (c). ${ }^{33)}$

\section{La-vacancy effect}

So far, $\mathrm{La}_{10}\left(\mathrm{Si} / \mathrm{GeO}_{4}\right)_{6} \mathrm{O}_{3}$ systems were focused, which do not have $\mathrm{La}$ vacancies. As reported experimentally, ionic conductivities depend on the La content $x$ of $\mathrm{La}_{9.33+x}\left(\mathrm{SiO}_{4}\right)_{6} \mathrm{O}_{2+1.5 x}$. Such an effect can be argued to make a comparison with the stoichiometric system of $\mathrm{La}_{9.33}\left(\mathrm{SiO}_{4}\right)_{6} \mathrm{O}_{2}$. Then the similar first-principles calculations were performed for $\mathrm{La}_{9.33}\left(\mathrm{SiO}_{4}\right)_{6} \mathrm{O}_{2}$, and it was found that the conduction mechanism is identical with that in $\mathrm{La}_{10}\left(\mathrm{SiO}_{4}\right)_{6} \mathrm{O}_{3}$ but the potential barriers for conduction along and normal to the $c$ axis are 0.29 and $0.38 \mathrm{eV}$, respectively. ${ }^{32)}$ Namely, in the presence of La vacancies, the potential barrier along the $c$ axis becomes larger while that normal to the $c$ axis smaller. This may be because the potential energy surface of $\mathrm{La}_{9.33}\left(\mathrm{SiO}_{4}\right)_{6} \mathrm{O}_{2}$ is more strongly modulated by $\mathrm{La}$ vacancies than that of $\mathrm{La}_{10}-$ $\left(\mathrm{SiO}_{4}\right)_{6} \mathrm{O}_{3}$. The similar argument was also made for interstitial oxygen ion sites in Sec. 3. It seems that La-vacancies and the resultant lowered symmetry can promote oxygen diffusion perpendicular to the $c$ axis.

\section{Conclusions}

Ionic conduction mechanisms of apatite-type structured lanthanum silicate and germanate were investigated by first-principles calculations. Although a range of ionic conduction mechanisms were proposed so far by experiments and atomistic simulations, it was found from first-principles calculations that the interstitialcy mechanism via $\mathrm{O} 4$ ions and/or $\mathrm{Si} / \mathrm{GeO}_{4}$ tetrahedra can reasonably explain the excellent ionic conductivities. Interstitial oxygen ions and oxygen ions at regular lattice sites undergo cooperative motion. It is worth mentioning that the interstitialcy mechanism 
can be applied to any ionic conduction directions in both the systems. In this class of materials, dopant such as $\mathrm{Mg}^{2+}$ and $\mathrm{Al}^{3+}, 36$ ) and defects like $\mathrm{Si}^{4+}$ vacancies ${ }^{37)}$ might be important for materials design, which will also be addressed in more detail, leading to a guideline to realize further improvement of the rapid ionic conduction.

Acknowledgement This work supported by a Grant-in-Aid for Scientific Research on Innovative Areas "Nano Informatics" (grant numbers 25106002) from Japan Society for the Promotion of Science (JSPS). The author also acknowledges K. Toyoura (Kyoto Univ.), K. Imaizumi, and A. Nakamura (Nagoya Univ.) for their support and discussions.

\section{References}

1) S. Nakayama, H. Aono and Y. Sadaoka, Chem. Lett., 6, 431432 (1995).

2) S. Nakayama and M. Sakamoto, J. Eur. Ceram. Soc., 18, 1413-1418 (1998).

3) S. Nakayama, M. Sakamoto, M. Highchi and K. Kodaira, J. Mater. Sci. Lett., 19, 91-93 (2000).

4) H. Arikawa, H. Nishiguchi, T. Ishihara and Y. Takita, Solid State Ionics, 136, 31-37 (2000).

5) M. Higuchi, Y. Masubuchi, S. Nakayama, S. Kikkawa and K. Kodaira, Solid State Ionics, 174, 73-80 (2004).

6) H. Yoshioka, J. Alloy. Compd., 408-412, 649-652 (2006).

7) H. Yoshioka, J. Am. Ceram. Soc., 90, 3099-3105 (2007).

8) H. Yoshioka, Y. Nojiri and S. Tanase, Solid State Ionics, 179, 2165-2169 (2008).

9) K. Imaizumi, K. Toyoura, A. Nakamura and K. Matsunaga, J. Phys.-Condens. Mat., 27, 365601 (2015). Available on: http://dx.doi.org/10.1088/0953-8984/27/36/365601.

10) J. R. Tolchard, M. S. Islam and P. R. Slater, J. Mater. Chem., 13, 1956-1961 (2003).

11) M. S. Islam, J. R. Tolchard and P. R. Slater, Chem. Commun., 1486-1487 (2003).

12) J. E. H. Sansom, D. Richings and P. R. Slater, Solid State Ionics, 139, 205-210 (2001).

13) H. Okudera, Y. Masubuchi, S. Kikkawa and A. Yoshiasa, Solid State Ionics, 176, 1473-1478 (2005).

14) E. Kendrick, M. S. Islam and P. R. Slater, J. Mater. Chem., 17, 3104-3111 (2007).

15) E. Béchade, O. Masson, T. Iwata, I. Julien, K. Fukuda, P. Thomas and E. Champion, Chem. Mater., 21, 2508-2517 (2009).
16) A. Jones, P. R. Slater and M. S. Islam, Chem. Mater, 20, 50555060 (2008).

17) R. Ali, M. Yashima, Y. Matsushita, H. Yoshioka, K. Ohoyama and F. Izumi, Chem. Mater., 20, 5203-5208 (2008).

18) E. Kendrick, M. S. Islam and P. R. Slater, Chem. Commun., 715-717 (2008).

19) S. S. Pramana, W. T. Klooster and T. J. White, Acta Crystallogr. B, 63, 597-602 (2007).

20) L. León-Reina, E. R. Losilla, M. Martínez-Lara, S. Bruque and M. A. G. Aranda, J. Mater. Chem., 14, 1142-1149 (2004).

21) P. M. Panchmatia, A. Orera, G. J. Rees, M. E. Smith, J. V. Hanna, P. R. Slater and M. S. Islam, Angew. Chem., Int. Edit., 50, 9328-9333 (2011).

22) K. Toyoura, A. Nakamura and K. Matsunaga, J. Phys. Chem. $C, 119,8480-8487$ (2015).

23) K. Toyoura, N. Hatada, Y. Nose, I. Tanaka, K. Matsunaga and T. Uda, J. Phys. Chem. C, 116, 19117-19124 (2012).

24) P. E. Blöchl, Phys. Rev. B, 50, 17953-17979 (1994).

25) G. Kresse and D. Joubert, Phys. Rev. B, 59, 1758-1775 (1999).

26) J. P. Perdew, K. Burke and M. Ernzerhof, Phys. Rev. Lett., 77, 3865-3868 (1996)

27) G. Henkelman, B. P. Uberuaga and H. Jónsson, J. Chem. Phys., 113, 9901-9904 (2000).

28) L. León-Reina, J. M. Porras-Vázquez, E. R. Losilla and M. A. G. Aranda, Solid State Ionics, 177, 1307-1315 (2006).

29) L. León-Reina, E. R. Losilla, M. Martínez-Lara, S. Bruque, A. Llobet, D. V. Sheptyakov and M. A. G. Aranda, J. Mater. Chem., 15, 2489-2498 (2005).

30) R. Ali, M. Yashima, Y. Matsushita, H. Yoshioka and F. Izumi, J. Solid State Chem., 182, 2846-2851 (2009).

31) J. E. H. Sansom, J. R. Tolchard, M. S. Islam, D. Apperley and P. R. Slater, J. Mater. Chem., 16, 1410-1413 (2006).

32) K. Matsunaga and K. Toyoura, J. Mater. Chem., 22, 72657273 (2012).

33) K. Imaizumi, K. Toyoura, A. Nakamura and K. Matsunaga, J. Ceram. Soc. Jpn., 125, 105-111 (2017). Available on: http:// doi.org/10.2109/jcersj2.16260.

34) A. A. Bolzan, C. Fong, B. J. Kennedy and C. J. Howard, Acta Crystallogr. B, 53, 373-380 (1997).

35) K. Imaizumi, K. Toyoura, A. Nakamura and K. Matsunaga, Solid State Ionics, 262, 512-516 (2014).

36) T. Liao, T. Sasaki and Z. Sun, Phys. Chem. Chem. Phys., 15, 17553-17559 (2013)

37) K. Fukuda, T. Asaka, S. Hara, M. Oyabu, A. Berghout, E. Béchade, O. Masson, I. Julien and P. Thomas, Chem. Mater., 25, 2154-2162 (2013).

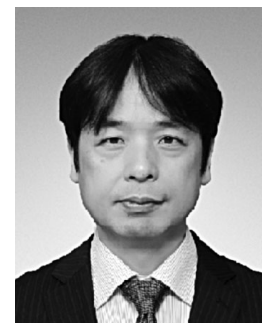

Katsuyuki Matsunaga received his Ph.D in 1997 from Kyoto University, and joined Japan Fine Ceramic Center (JFCC) as a researcher. From 2001, he worked as an Assistant Professor at The University of Tokyo, and moved to Kyoto University in 2005 as an Associate Professor. He has been a Professor at Nagoya University since 2011, and is also now a guest researcher at Nanostructures Research Laboratory of JFCC. His research focuses theoretical modeling of point defects, grain boundaries, and interfaces in ceramic materials. 